This item was submitted to Loughborough's Research Repository by the author.

Items in Figshare are protected by copyright, with all rights reserved, unless otherwise indicated.

\title{
When police treat straightforward answers as uncooperative
}

PLEASE CITE THE PUBLISHED VERSION

https://doi.org/10.1016/j.pragma.2017.05.012

\section{PUBLISHER}

(c) Elsevier

VERSION

AM (Accepted Manuscript)

\section{PUBLISHER STATEMENT}

This work is made available according to the conditions of the Creative Commons Attribution-NonCommercialNoDerivatives 4.0 International (CC BY-NC-ND 4.0) licence. Full details of this licence are available at: https://creativecommons.org/licenses/by-nc-nd/4.0/

\section{LICENCE}

CC BY-NC-ND 4.0

\section{REPOSITORY RECORD}

Antaki, Charles, and Elizabeth Stokoe. 2019. "When Police Treat Straightforward Answers as Uncooperative". figshare. https://hdl.handle.net/2134/25322. 
When police treat straightforward answers as uncooperative

Accepted by the Journal of Pragmatics, May 2017

Keywords: police interviews, suspects, witnesses, cooperative principle, institutional talk

Charles Antaki and Elizabeth Stokoe

both at:

Department of Social Sciencxes

Loughborough University

Loughborough LE11 3TU

England

Abstract

In formal police interviews, interviewers may have institutionally mandated reasons for following up even apparently fully co-operative answers with questions that imply that the interviewee is in fact (knowingly or unknowingly) being uncooperative. From a sample of over 100 UK interviews with suspects arrested for minor offences, and 19 interviews with witnesses alleging sexual assault, we identify and analyse follow-up questions which do not presume that interviewees' apparently 'normal' answers respect the Gricean maxims of quantity, quality, relevance or manner. We identify three institutional motivations working to over-ride the normal communicative contract: to 'get the facts straight'; to prepare for later challenges; and pursue a description of events that more evidently categorizes the alleged perpetrators' behaviour as criminal. 
Are answers to questions usually assumed to be co-operative? Certainly Grice's familiar principle ("make your conversational contribution such as is required ... by the accepted purpose or direction of the talk", Grice, 1989, p. 26) seems to be generally assumed to be operative in everyday conversation. But rules for everyday conversational engagement are adapted when institutional frames (the court, the confessional, the surgical theatre, etc.) are in play. This article is about the adaptations visible in one particular institution, the formal police interview.

There are many ways of conceiving of how institutions alter everyday norms. Drew and Heritage (1992b) give us a useful set of dimensions on which to distinguish everyday from institutional talk: the latter will have some predictable, known-to-participants objective; it will impose differential rights on what turns to take, and when to take them, on those involved; and it will require or constrain certain kinds of inferences that participants can make about each other's' conduct. Our interest in this article is in those inferences, and, following Houtkoop (2000, chapter 4), how the assumption of cooperation fares under a certain combination of institutional objective and institutional constraint. Specifically, we shall be examining how the police interview allows (or indeed requires) the suspension of the Gricean presumption of co-operation (Grice 1975/1989) between interlocutors.

It is certainly not every institutional encounter that will set Gricean maxims to one side; the social cost of doubting one's interlocutor's co-operativeness is a high one to bear. But there will be some institutions which are willing to pay the price; or, to put it more analytically, there will be some institutional contexts whose inferential schemata (as Levinson, 1992, p 72 calls them) will require the interviewer to apply a less co-operative and more sceptical standard to what their interlocutors say.

The institutions that seem likely candidates for such scepticism are those in which its representatives are mandated, by some higher authority, to pursue versions of events that may not be in the interlocutor's best interests to reveal, and which the interlocutor may be motivated to disguise by apparent (but misleading) co-operation. It's possible that scepticism may occasionally rear its head even in apparently non-adversarial encounters (e.g., a doctor might doubt the veracity of a patient's reports of their drinking or smoking, or a teacher might disbelieve a pupil's account for not doing their homework). A more promising environment might be the more aggressive brand of news interviewing (for which see, for example, Clayman et al, 2006, on the erosion of deference in the White House press corps' questions over the years). Legal dispute in general may well be a felicitous environment for suspension of conversational cooperation (as argued, for example, by the legal scholar Andrei Marmor, e.g., Marmor, 2009, esp. ch. 5), But we have our eye on one institutional setting, the police interview, where there is a legal inferential framework that makes scepticism a sharply and standardly mandated obligation. In this report, we detail how a police interviewer might question even ostensibly co-operative responses, and follow them up to seek out the most forensically complete version of events, whether in their interviewee's favour or not. 
The reason for choosing police interview is that the institutional demands of the interviewers' role are clear - and have an intriguing internal conflict. The institutional obligations are formally set out in the Police and Criminal Evidence Act (1984), usually referred to as PACE. How, though, to put this into practice? $P A C E$ is a legal statute, not designed for practical application, so working officers will turn to the College of Policing's documentation (here referred to for convenience as CoP) of authorised professional practices (College of Policing, n.d.) which sets standards of practical police work in England and Wales. That document gives extensive guidelines and detailed recommendations on interviewing, which expand on the drier legal statute PACE. The recommendations cover a great deal of ground, but there is a conflict at the heart of what they oblige the officer to do. These two extracts from $\mathrm{CoP}$ illustrate what we mean:

"Style matters because it affects the motivation of the interviewee to be accurate and relevant in their replies. Establishing a rapport means being genuinely open, interested and approachable, as well as being interested in the interviewee's feelings or welfare." (College of Policing, section 1; emphasis added).

Even though the ostensible differences between the interests of a witness and a suspect (one neutral, one defensive) might suggest divergent treatment by the interviewing officer, in fact the guidelines overlap: the strictures on rapport and truth-seeking apply to both:

"The aim of investigative interviewing is to obtain accurate and reliable accounts from victims, witnesses or suspects about matters under police investigation.

To be accurate, information should be as complete as possible without any omissions or distortion.

To be reliable, the information must have been given truthfully and be able to withstand further scrutiny, eg, in court." (College of Policing, Principle 1; emphasis added).

Establishing rapport would normally involve assuming your interlocutor was playing to the same standards of co-operation as you were; but the officer is enjoined to make sure that what the interocutor says is complete, accurate and truthful, which implies that the officer will, at least sometimes, make the contrary assumption.

The difference from everyday interlocutors' terms of engagement is signalled early on in the interviews, as the following typical exchange shows:

Example $1 \mathrm{PN}-65^{1}$

$01 \rightarrow$ Po1: $\begin{aligned} & \text { F'the benefit of the tape can you please um: } \\ & 02 \rightarrow \\ & 03\end{aligned} \quad$ your full name an' date o'birth for me please.
$(0.4)$

${ }^{1}$ All names and other identifiers have been changed in the data shown in this article 
As Stokoe (2009) argues, the preface "for the benefit of the tape", makes it clear that here there are institutional reasons why normal presumptions about the question might be over-ridden, perhaps risking the rapport the interviewers might otherwise establish with the interviewee. That is the tension we shall be exploring in the article. The interviewees' answers to questions may look perfectly co-operative as to relevance, truth, extent, and manner of delivery ; but on occasion, the interviewer will issue a follow-up question which makes no such presumption, and puts rapport at risk. What do such exchanges look like, and what instituional purpose do they serve?

\section{Data}

\section{Larger corpus: suspect interviews.}

This dataset ${ }^{2}$ comprises 118 interviews between different police officers and suspects in a constabulary area of the UK police service. Audio cassettes of old, completed crime cases were made available by police administrators, and were digitally recorded and anonymized on-site at a secure storage facility. Interviews ran for about an hour on average. Data Processing Agreements to work with the data were drawn up between the service and the authors' University. Names that could identify persons and places, including police officers, have been altered. Of the 122 recordings made available, 12 were unanalysable (because tape quality was too poor), and in 6 the suspect maintained 'no comment' throughout, or virtually throughout. This left 104 interviews which allowed us to identify pragmatically odd follow-up questions. More detailed information about these interviews is available in Stokoe and Edwards (2008).

Smaller corpus: witnesses, with learning disabilities. A police force in England allowed us access to 20 videotapes of interviews, anonymized on-site, again from old and archived cases, but here involving witnesses with intellectual disabilities. The interviews were recorded between 2010 and 2013 by trained officers. Interviews lasted between 21 minutes and just over two hours. All witnesses were being questioned on their allegations of being sexually assaulted or raped. They all had some kind of what the police called "learning disability", but the case files were very variable in specifying the interviewee's specific diagnosis. of the 20 recordings made available, one was incomplete. Interviews ran for over an hour on average. More detailed information about these interviews is available in Antaki et al (2016).

\section{Pre-Analysis: boundary cases}

In the extracts below, SUS and WIT denote interviews with suspects and with witnesses, respectively. Speakers are identified only as PO (police officer; P01, PO2 if necessary) and either SUS or WIT.

\footnotetext{
2 The corpus was collected as part of ESRC grant number RES-148-25-0010 "Identities in neighbour discourse: Community, conflict and exclusion" held by Elizabeth Stokoe and Derek Edwards.
} 
A note on transcription: the data extracts are presented in a light version of Gail Jefferson's notation, widely used in Conversation Analysis and other interactional studies. Accessible guides to her notation conventions are published in a number of texts (eg. ten Have, 2007; Liddicoat, 2011) and a full exposition is given in Jefferson (2004)

\section{Boundary cases.}

Before we get to the analysis, there are two kinds of follow-up questions that the police interviewers ask which should be set aside from the ones that we're interested in. Although they come in the environment of a question being asked and answered, neither breaks the co-operative contract.

a) Simple follow-ups. The obvious boundary case, of course, is the case where the PO follows up a straightforward answer- that is, those questions which probe at an answer that is following co-operative maxims in the expected way: not obviously a lie, saying as much as is required, saying it straightforwardly and relevantly to the question. In such cases, whatever the interviewer's apparent motivation in following it up, it is not suspicion that the interviewee is being unco-operative.

\section{Example 2. SUS 11}

168 07.30 P01 pursues more information about the event

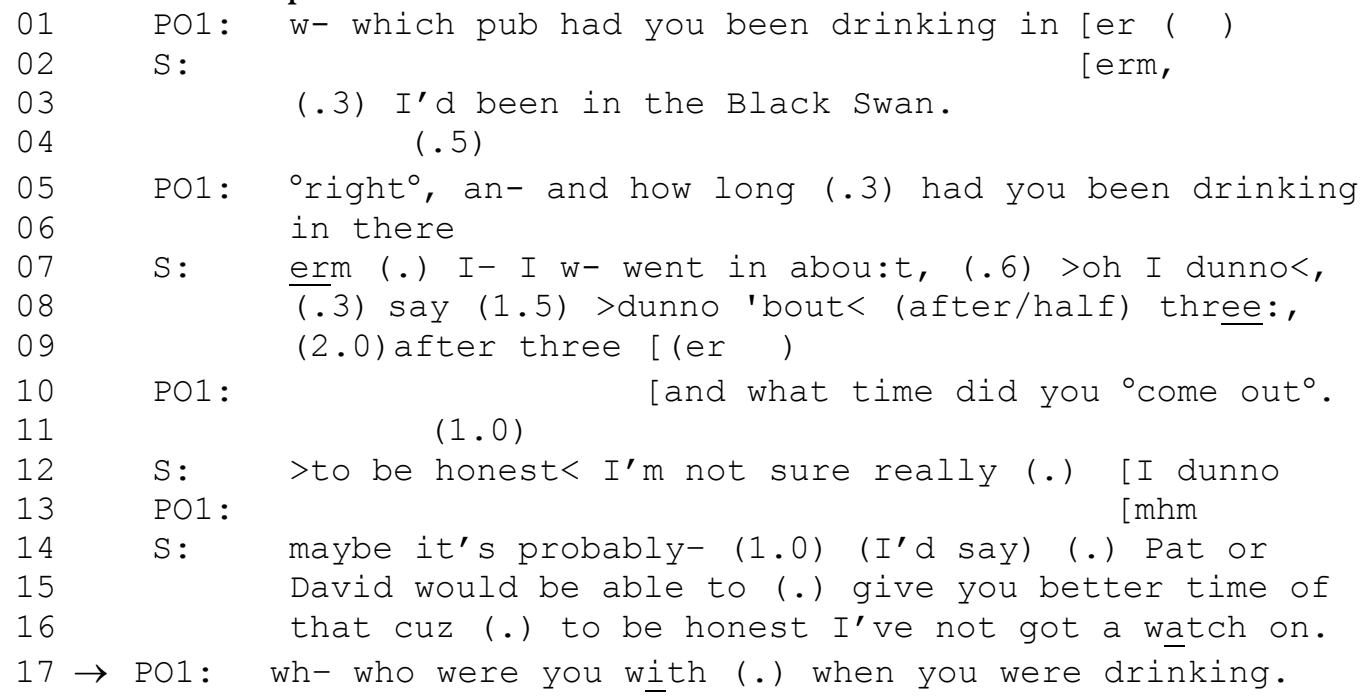

In the above example, the suspect's responses to each of the PO's questions is although occasionally vague - apparently acceptably detailed, apparently true, and so on; the reason for the interviewer's follow-up question at line 17 is merely a matter of proceeding to collect further information about the suspect's drinking, not encompassed by the first question about physical location.

b) Follow-ups warranted by obvious deficiencies or other un-cooperativeness in the answer. There is a more useful boundary case, where the PO issues a follow-up question which looks at first sight like the ones we go on analyse - but is in fact perfectly well warranted by the obviously uncooperative nature of the IE's previous answer. 
Here PO's follow-up question is warranted by the referential ambiguity of what the IE said.

Example 3. SUS 118, 04.3

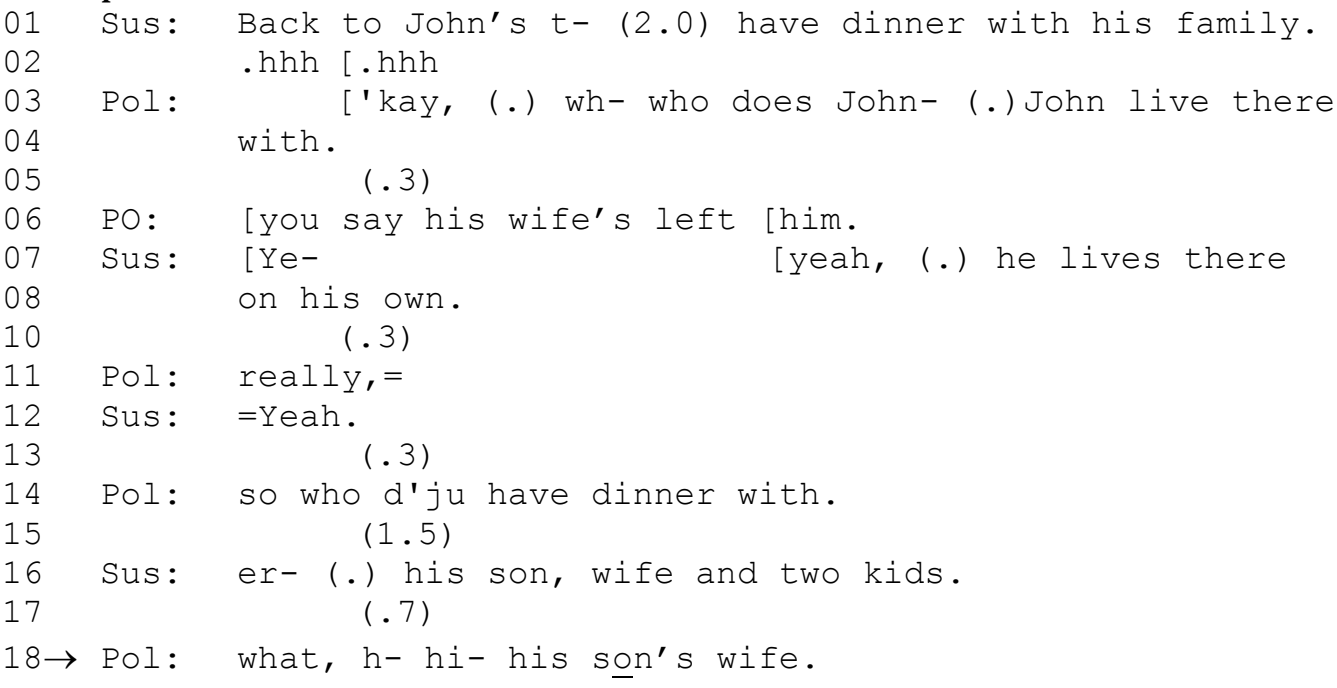

The suspect has said that Keith lived on his own, but that makes having dinner with him and his son, wife and two kids an obvious puzzle, resolved by a simple follow-up question at line 18 with a candidate answer (it's Keith's son's wife, not Keith's).

Example 4. WIT 14, 15.55

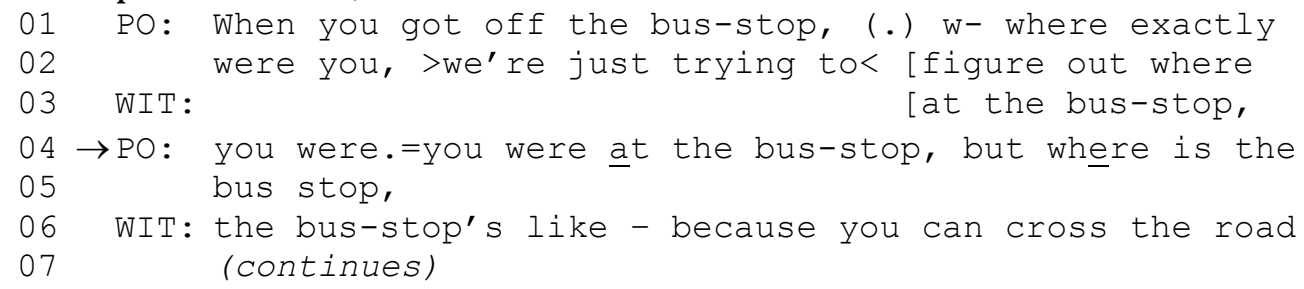

In Example 4 above, again there is a simple deficiency in the IE's answer - it manifestly doesn't add anything (it fails the maxim of quantity) and the puzzle is again addressed by a simple next question (line 4).

Now let us turn to the corpus of interest. Our rule for inclusion was straightforward: we took in any exchange that featured a sceptical follow-up to an ostensibly co-operative answer to a question. The crucial point in all of the cases below is that the interviewee seems to have answered a police officer's question co-operatively, speaking relevantly, truthfully and plainly, and saying as much as is required. So the officer's follow-up can't be attributed to any obvious pragmatic deficiency in the interviewee's answer. What do such exchanges look like, and what institutional interests might they serve?

\section{$\underline{\text { Analysis }}$}

First, we give examples, for illustration and without much commentary, of follow-up questions which query the adherence to cooperative maxims of 
(apparently unexceptionable) answers. Then we move on to show more analytically what institutional benefits such questions yield.

Examples of follow-ups which query adherence to Quantity

The interviewer, on occasion, did not treat the interviewee as having said all that they ought - even though (it seems to us intuitively) that what the question asks for would normally have been easily inferable, without effort, from the answer.

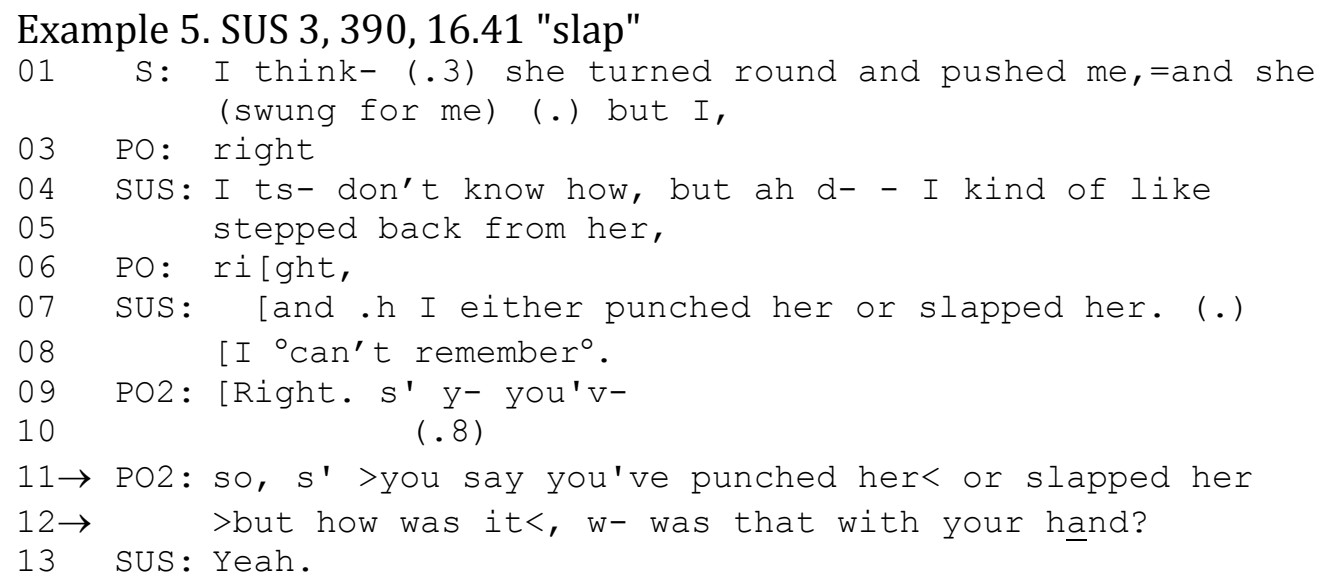

Slapping or punching would ordinarily and automatically entail using (only) the hand - yet PO asks (lines 11-12) for explicit confirmation. (Recall that we offer no further analysis at this point - that comes after we've set all these out as examples of scepticism about each of the maxims)

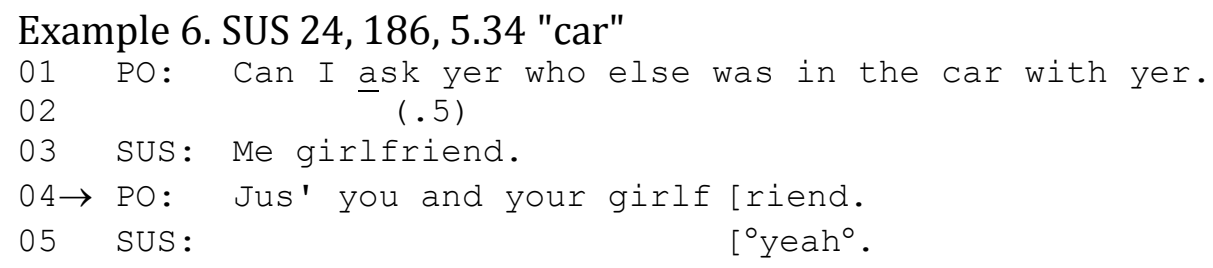

Here the PO ignores the usual presumption that SUS's answer respects the maxim of quantity, and specifies everyone who qualified as being in the car.

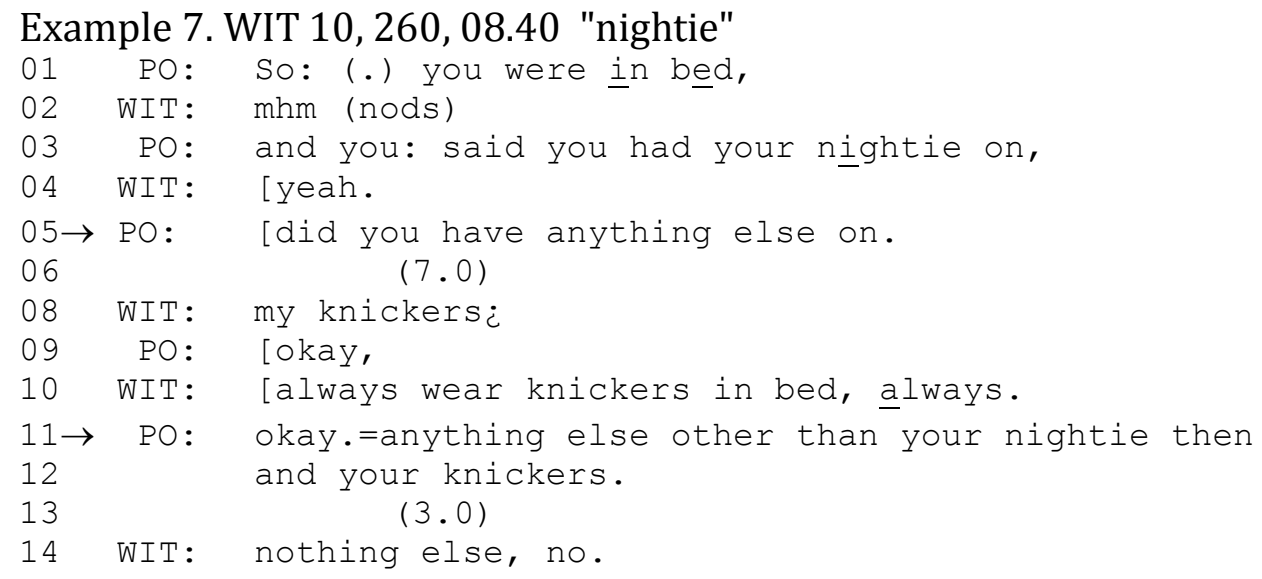


And here again the PO (twice) ignores the presumption that the witness had listed all the relevant information (in this case, wearing a nightie would, we think, normally not entail wearing other items of clothing; wearing the nightie plus knickers still less so).

Examples of follow-ups which query adherence to Quality

At the less interesting end of this continuum of quality-querying PO's questions are those that treat an apparently full response as requiring simple "clarification". To do so, of course, implies that the answer was uncooperative (in truth-telling), plausible though it might have looked in everyday conversation between peers. The two examples below show the PO following up in this mode, the first with a formulation (Heritage and Watson 1980) and the latter with a yes-preferring polar question (Raymond, 2003).

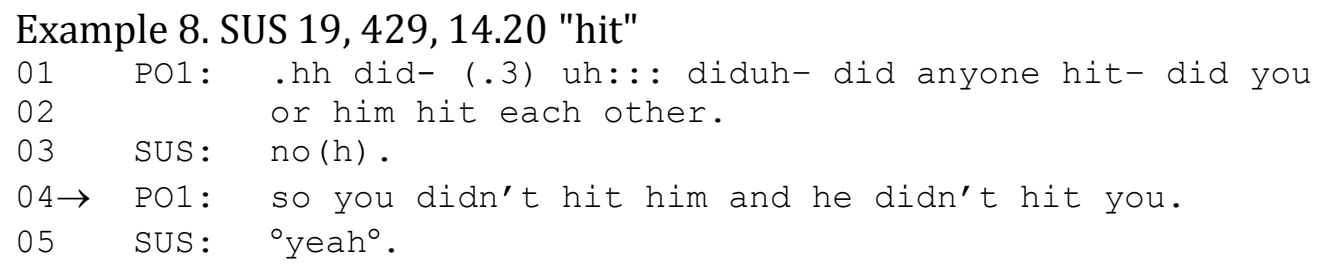

Example 9. SUS 21, 166, 06.20 "with anyone"

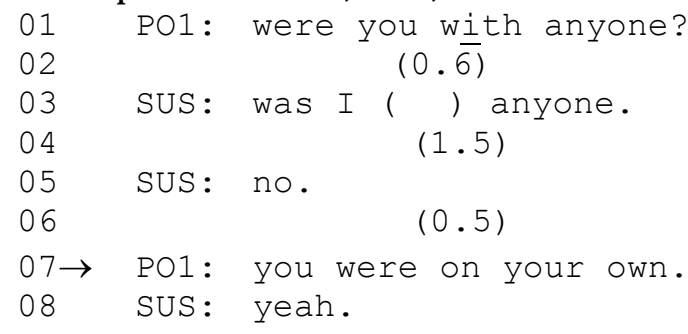

The more interesting end of the spectrum of quality follow-ups are those where the confirmation is not a mere check of what has been explicitly said, but brings out something that is already (and normally "obviously") implicated by the suspect's previous answer (- and, as we shall later see, that something is legally important). Here is an example:

Example 10. SUS 52, 178, 05.40

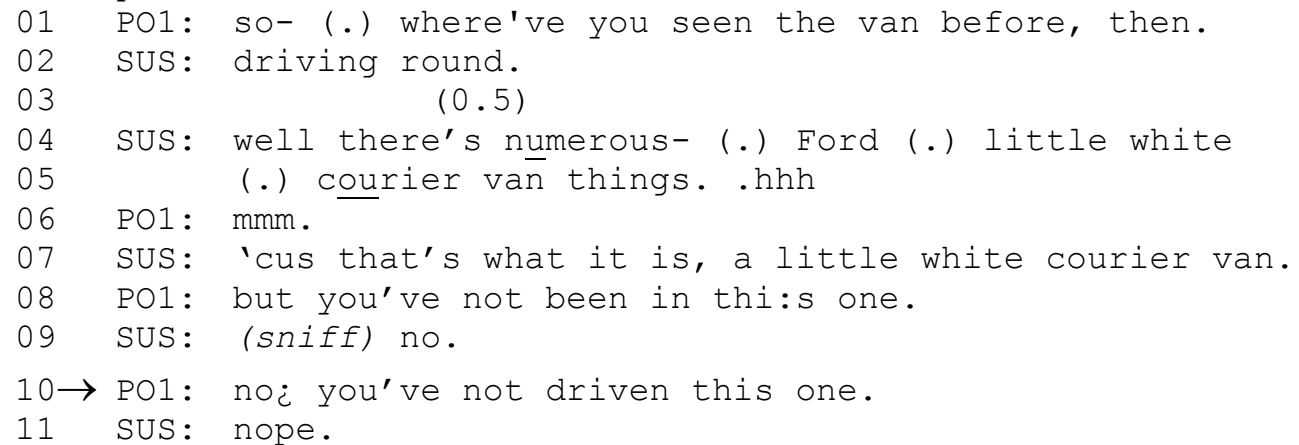

SUS not "being in" this van obviously implies, a fortiori, not driving it; nevertheless PO treats him as not having told the truth, and ups the ante by 
specifically putting that (more criminally serious) version of events to him (- and this is the kind of institutional objective we shall spell out later).

Examples of follow-ups which query adherence to Manner

There were some cases in our data where the manner in which the IE designed their answer, though it would (probably) pass in everyday British English conversation as being merely ordinarily euphemistic, was treated by the police interviewer as uncooperatively failing the maxim of manner rather than merely flouting it for ordinary effect.

Example 11. SUS 51, 451, 19.28

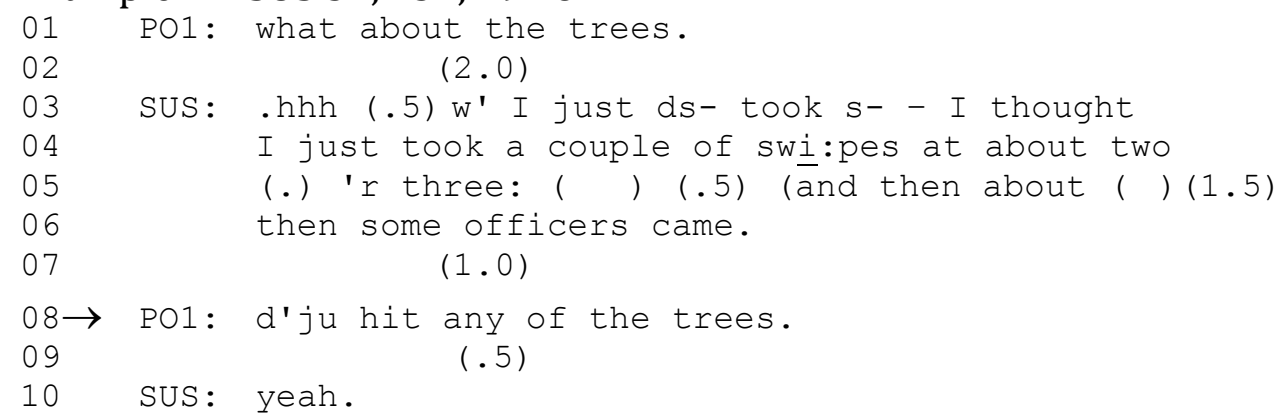

Here the SUS's "couple of swipes" would pass muster, probably not even as any sort of euphemism, in everyday talk; but the PO treats it as evading the more explicit (and criminally relevant) "hit".

In the next example, the interviewee is a witness alleging being raped in a prison cell.

Example 12. WIT 13, 769, 40.50

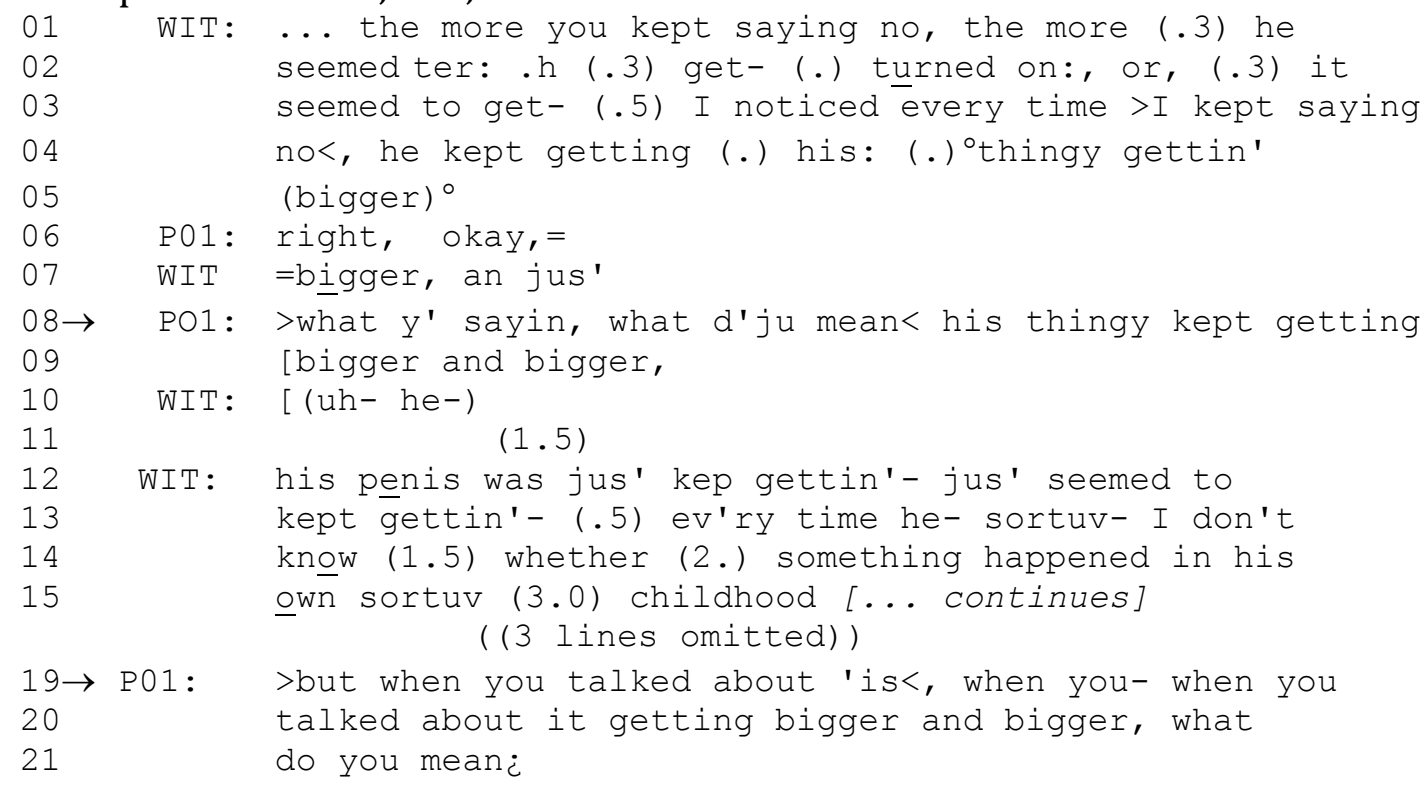

'His thingy' would be understood as a polite - but obvious - euphemism in everyday British talk; but PO at line 8 treats it as inappropriate in style and requires the witness himself to pronounce the word "penis". And again at line 19, PO insists on not treating "getting bigger and bigger" as a proper description, 
presumably angling for the more recordable "erect". The objective is, as before, to record (literally: in the case of vulnerable witnesses, the tape is played as evidence) an account that makes the alleged offence as unambiguous as possible. Again, this is a hint of the analysis to come.

\section{Examples of follow-ups which query adherence to Relevance}

Occasionally in the data, even such an allegedly fundamental (Sperber and Wilson 1986, and subject to a long debate since then; see for example Moeschler, 2013) principle as relevance seems to be disputable in some circumstances. For example, in the case below, the interviewee gives an answer that would (we think) pass muster as at least tangentially informative about the question, but the PO nevertheless challenges it:

Example 13. SUS 62, 71, 03.33

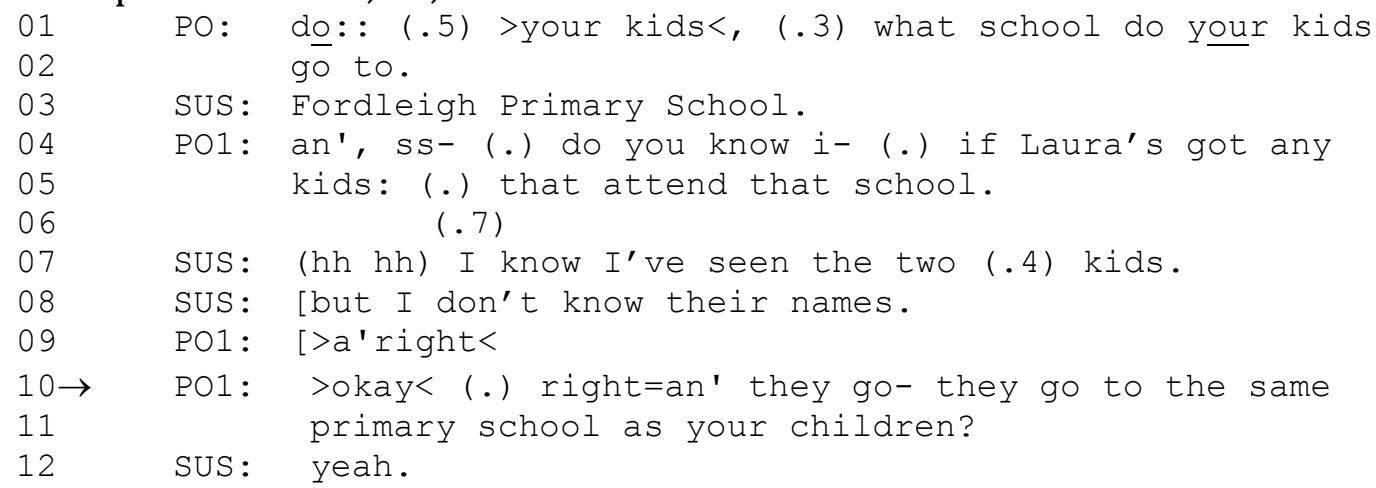

SUS's claim that she's 'seen' the two kids but doesn't know their names, might normally allow the inference that she (also) doesn't know whether they go to the same school as hers. But PO treats her answer as not relevant to the question, and reissues it explicitly (and indeed discovers that the 'normal' implicature would have been quite wrong). In the example below, SUS disputes the premise of the PO's question, but his challenge is taken to be irrelevant:

Example 14. SUS 104, 164, 10.40

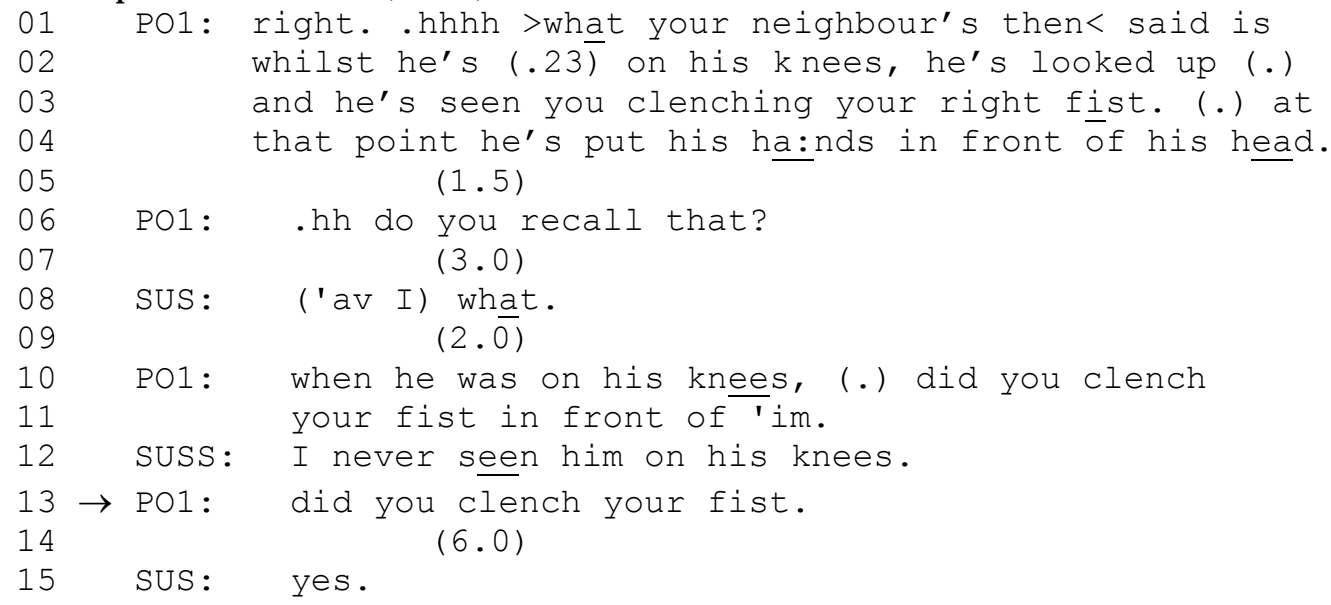

By reissuing did you clench your fist, PO dismisses SUS's answer as not relevant, and - as above - brings out a more damaging admission. 
Having seen a bare list of examples of the kind of follow-up questions we have in our sights, let us now move to considering the institutional objectives that they might be serving.

The institutional benefits of querying apparently unexceptionable answers

\section{a) Testing, or establishing, the credibility or completeness of the account}

The most basic imperative for the interviewing officers, in both the suspect and the witness cases, is to get the facts straight. The imperatives will be different, but overlapping; the suspects may want to elide the more criminal aspects of the events, and the witnesses may be confused (especially in this particular sample of interviews, when they are both intellectually impaired and are also reliving some distressing experiences). As in all the other cases, it is the PO's brief - while trying to maintain rapport with their interviewee - not to presume that what looks like their fully co-operative answer is actually as informative or as wellgrounded as it seems.

In the example below, even what seems to be a wholly complete, neutral answer to an apparently routine question is not taken at face value by the PO:

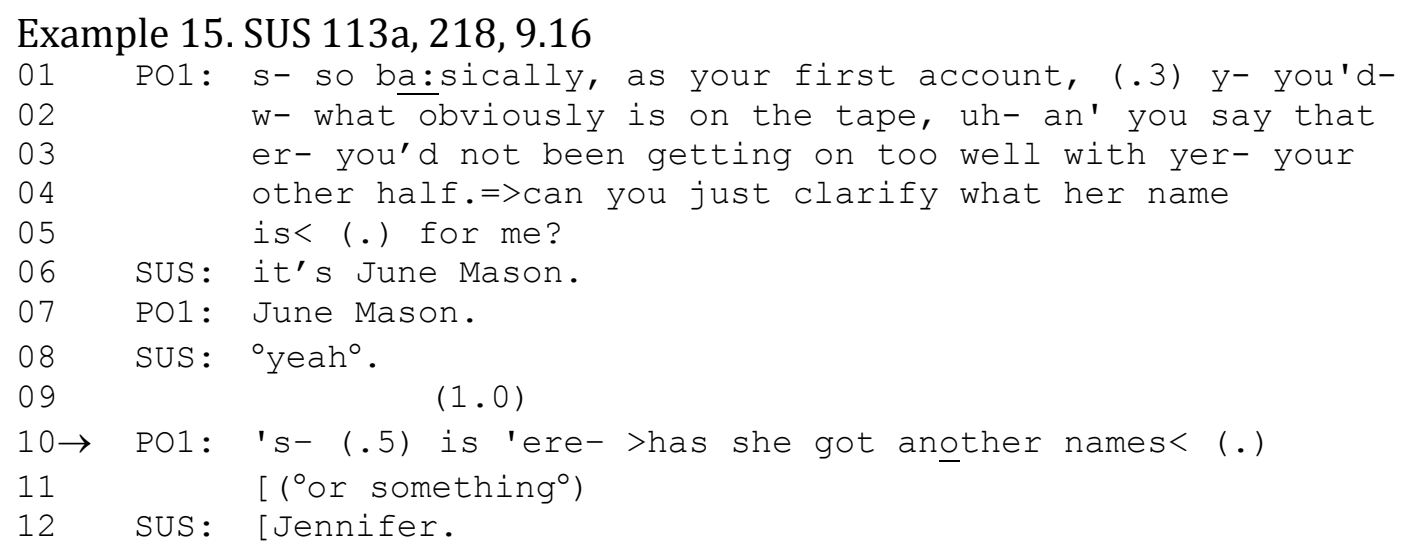

In the witness cases, the PO's concern to get the story straight may even lead to an exchange like the one below, which queries the witness's most basic authority in having evidence to back up her experience:

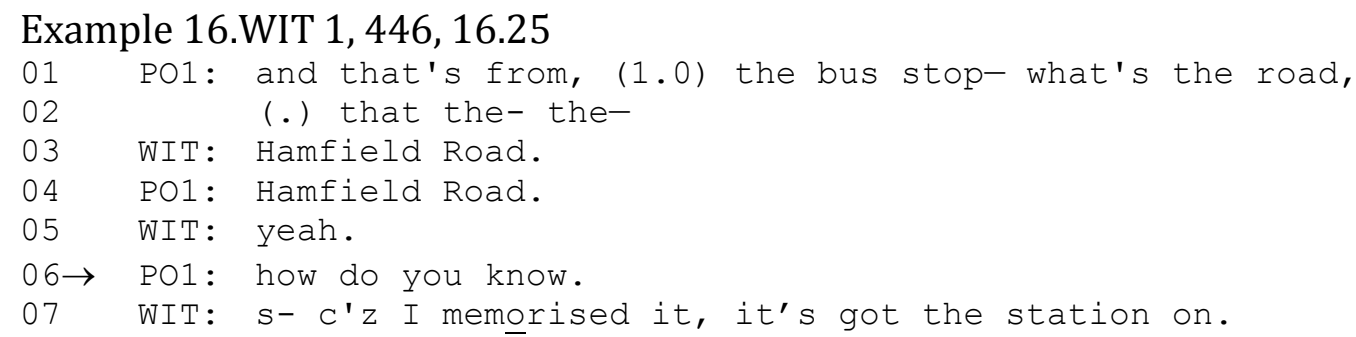

As this is a comparatively bland institutional objective (getting the story straight will be a requirement of many other institutional encounters, from primary-care history-taking (e.g. Maynard and Heritage 2005) to telephone helplines (e.g. 
Hepburn et al, 2014), we shan't dwell on them here but move on to institutional objectives more specific to the police: eliciting evidence.

At this point we might profitably look across to a rather different take on very similar data - Heydon's (2005) treatment of topic-shifting questions in police interviews. Heydon is concerned to reveal the directive power placed in the hands of the interviewer by the authority of their insitutional role, and one mechanism she identifies is topic-shifting. Consider this example (which we reproduce with much simplification of Heydon's transcription):

Reproduced from Heydon, 2005, p 107:

Suspect: the only thing I got was a CD and a roast from the fridge

PO: right why'd you take the roast in the fridge

Suspect: I was hungry

PO: all right did you take a Metallica tape from the bedroom

Heydon's interest is in the "all right" in the last line, and uses it to indicate a "shift of footing back to the original line of questioning" (Heydon p 107). Since the Gricean angle is not part of Heydon's objective (identifying structural stages in the interviews via topic-shift), she doesn't remark on the Gricean challenge involved. The suspect had - ostensibly - reported all that he had taken was a CD and a roast, but the interviewer checks a further item, treating the suspect as having failed the maxim of quantity in giving only a partial list of what he took. The more general approach to the overall structure of the interview - which is Heydon's general project - misses this more fine-grained analysis, but the two are nicely compatible.

\section{b) Preparing for more challenging questions later}

In many cases, the PO's follow-up question is not so much designed to reveal a more criminal intention or set of consequences (the interview isn't at that point in the proceedings) so much as to build up a narrative that may (sooner or later) lead to contradictions, inconsistencies or other implausibilities that can be put to the interviewee.

Here is an example where the follow-up question to an apparently unexceptionable answer yields an immediate challenge of inconsistency.

Example 17. SUS $111 \mathrm{~b}, 59,3.00$

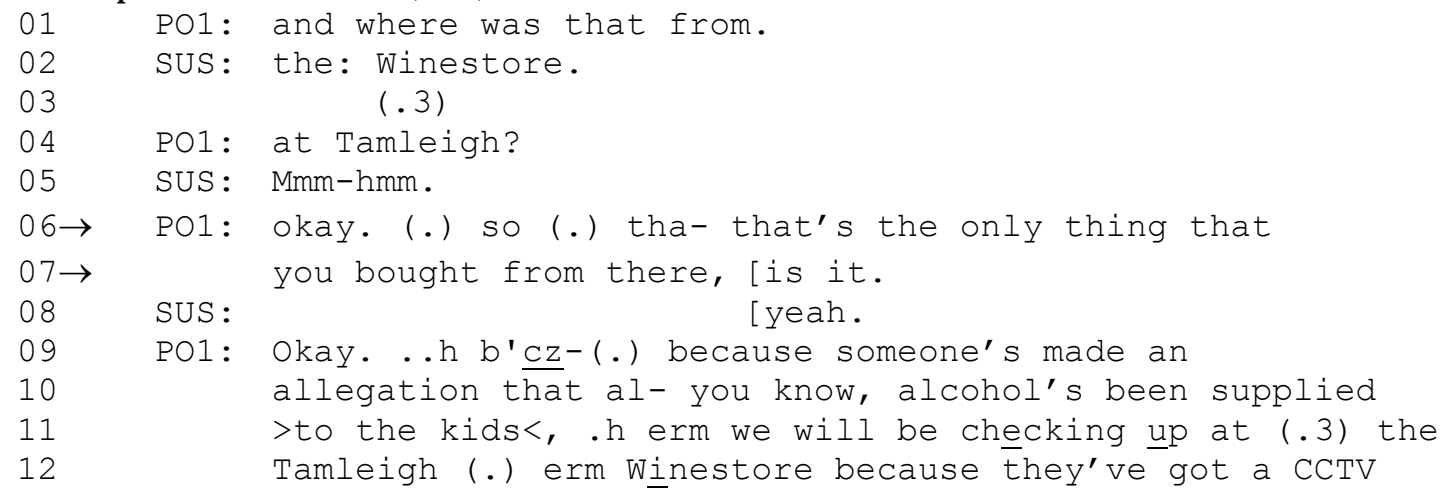




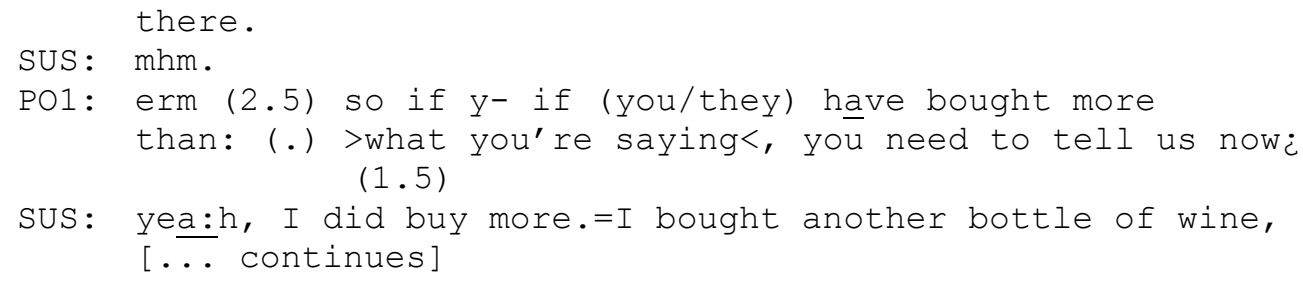

SUS's previous answer (not shown above) about what she had bought from the shop, though not obviously implausible, is queried by PO (at line 6) with a yesprojecting tag question (Heritage and Raymond, 2005). Her confirmation allows PO then to launch an immediate potential contradiction which SUS has to deal with; and she does so by conceding that, in fact, she did buy more (line 18). In the case below, the IE's answer is not taken as being of sufficient quality (though it seems firmly enough presented). IE saw nobody and spoke to nobody at the location of the alleged events. But PO pursues the issues, and introduces "a lady" who will, it transpires, later be a source of a witness statement implicating the suspect in a crime. The officer's first probe (line 7) is unnecessary if the SUS's first answer is to be accepted (if he hadn't seen anyone, he is unlikely to have spoken to anyone) but it serves to cement the denial and provide a basis for a starker challenge.

\section{Example 18. SUS $38145,4.40$}

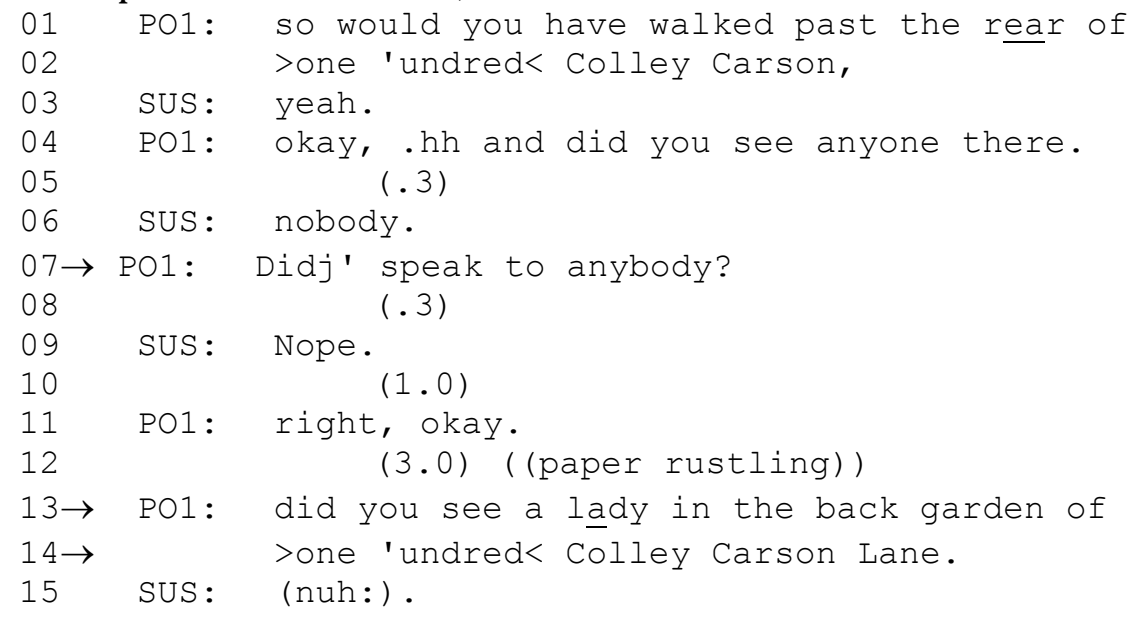

The second, and more specific, probe (lines 13-14) introduces "a lady" who becomes useful later in the interview, when PO confronts SUS with a direct report of his having been in that location, and committed various acts:

Example 19 (continuation after about 20 lines, from Example 18 immediately above)

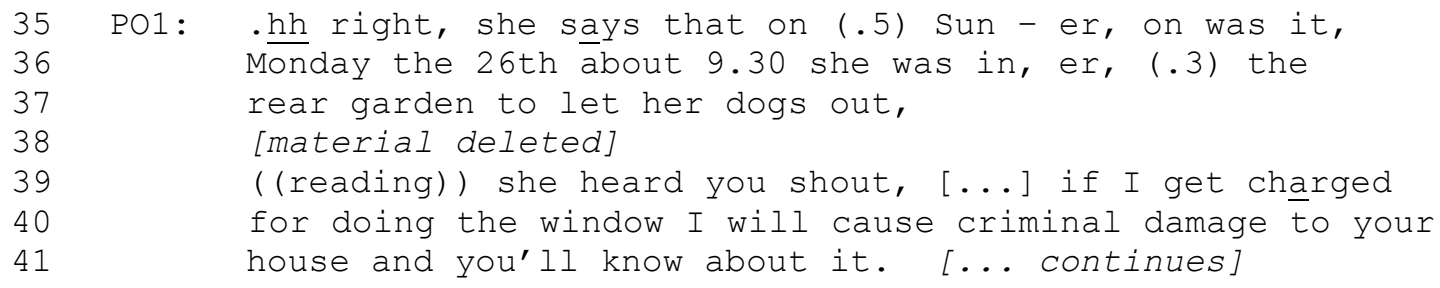


The follow-up, then, can be useful in preparing for a challenge (always in the direction of more incriminating evidence) of the IE's version of events, even if stated confidently. The next and last of the objectives we identify, however, goes a step further.

\section{c) Bringing forth more material relevant to a chargeable offence}

The most institutionally powerful use of follow-up questions is to elicit something which would help identify what criminal charge might be brought (either against the suspect in the interview, or, in the case of witnesses, against the alleged perpetrator). In Example 5 the "slap" was with the hand (rather than an object, so likely to lead to a lesser charge), in 11 the suspect admits hitting rather than swiping (so likely to be vulnerable to a more serious charge), and in 12 "thingy" in the witness's account gets translated into "penis" to better function as evidence in a charge of sexual assault. Let us look in more detail at other examples.

Intention. In some cases the drive behind PO's question was, as with "silly questions" (Stokoe and Edwards, 2008), getting on tape an admission from the suspect that his or her actions were performed with the intention to produce, or foreknowledge of, "various consequences (break, snap, smash), whose nature can be formulated or re-formulated forensically (e.g. as 'criminal damage')" (Stokoe and Edwards, 2008, 108). That is nicely illustrated in the case below, where SUS's apparently firm description of events is not taken as being of sufficient quality (- in other words, PO treats it as untruthful) in terms of its implications of intention.

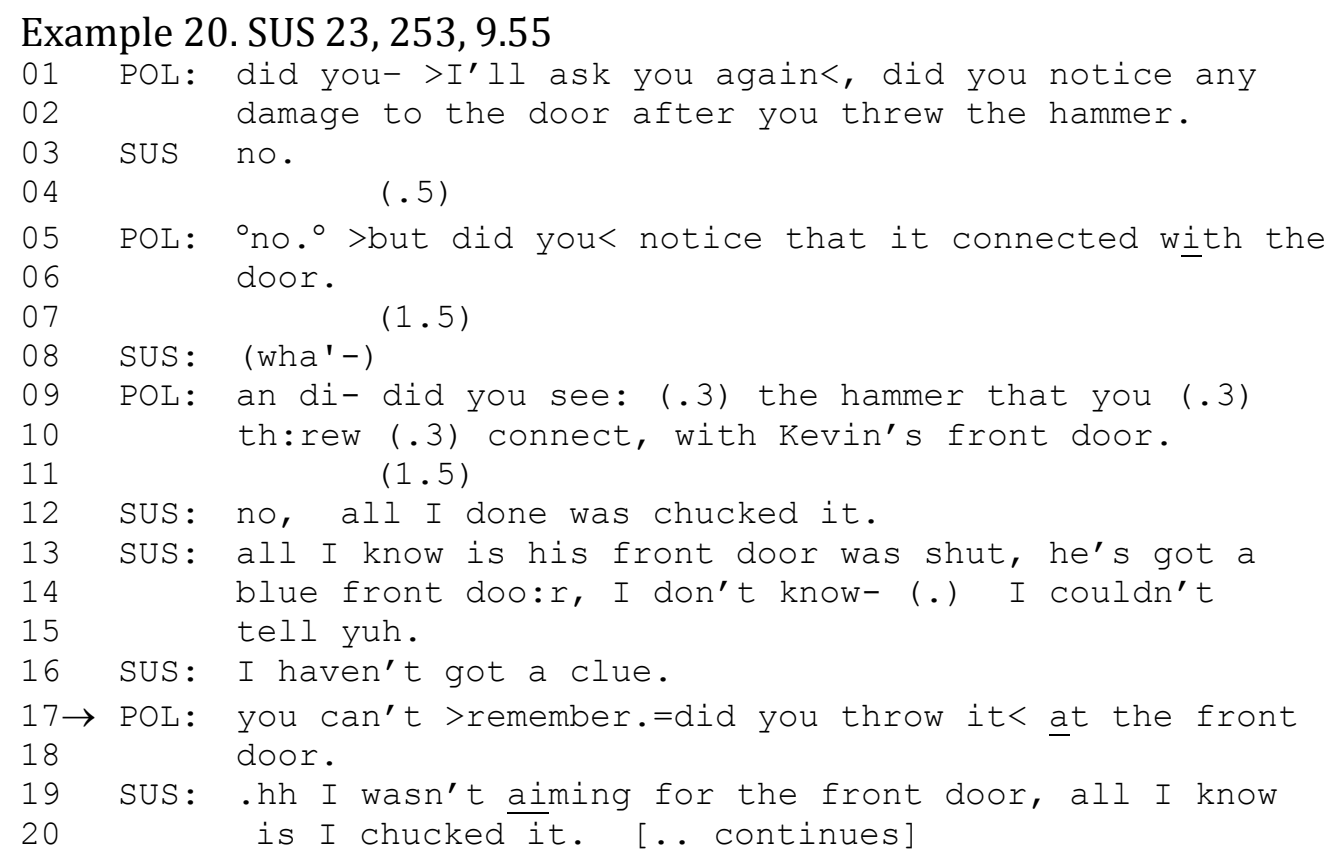

PO works up to his final question (line 17) in this stretch by first establishing that there might be damage to the door, or, failing an answer in the affirmative, that the hammer might at least have connected with the door. This also fails to solicit an admission, so the PO issues a bald direct question did you throw it at 
the front door?. "Throw at" would entail intention, so - were she to assent - make the SUS liable to a more aggravated charge.

Consequences In other cases of follow-up questions, it is not the intent of the act, but the nature of the act itself and its likely consequences. In the example below, the follow-up question (to, as always, an apparently unexceptionably complete answer) reveals a much more damaging description of events.

\section{Example 21. SUS 36, 121}

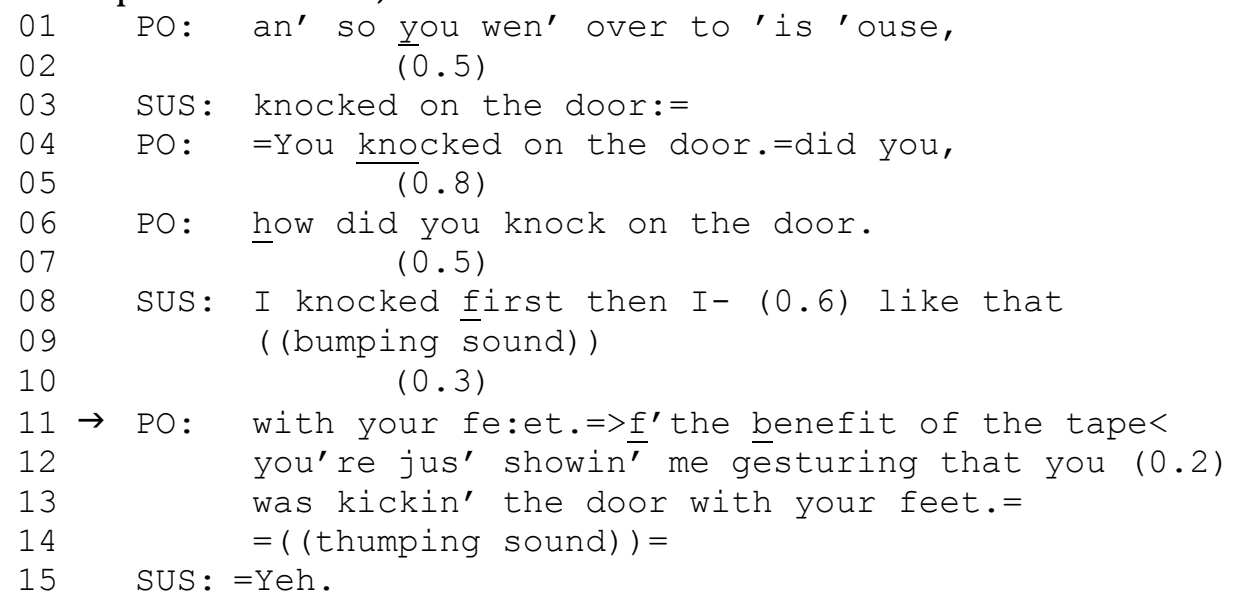

An ordinary interlocutor might have assumed (given the maxim of quantity) that SUS was saying all he needed to, i.e. that he was just knocking at his neighbour's door normally, with knuckles; but on PO's probing, it turns out that he used his feet as well (a usage hard to square with "knock", which at a push might extend to ringing a bell, pressing a buzzer, or rattling the letter-box; not kicking). Note that even then, the SUS avoids naming the action, in favour of miming it; it is left to the PO actually to articulate it as "kicking the door with your feet".

\section{Witness examples}

While it is obviously likely that POs will put follow up questions to this sort of incriminating use when the interviewee is a suspect, one might not predict that they would do so when the interviewee was a witness (indeed one alleging being the victim of a distressing crime). But here there is a need to establish the chargeability of someone, even if not the person being interviewed. Hence a follow-up question like the one below, when the witness is asked for information that would imply that the alleged perpetrator knew what he was doing.

Example 22. WIT 6, 1116, 31.20

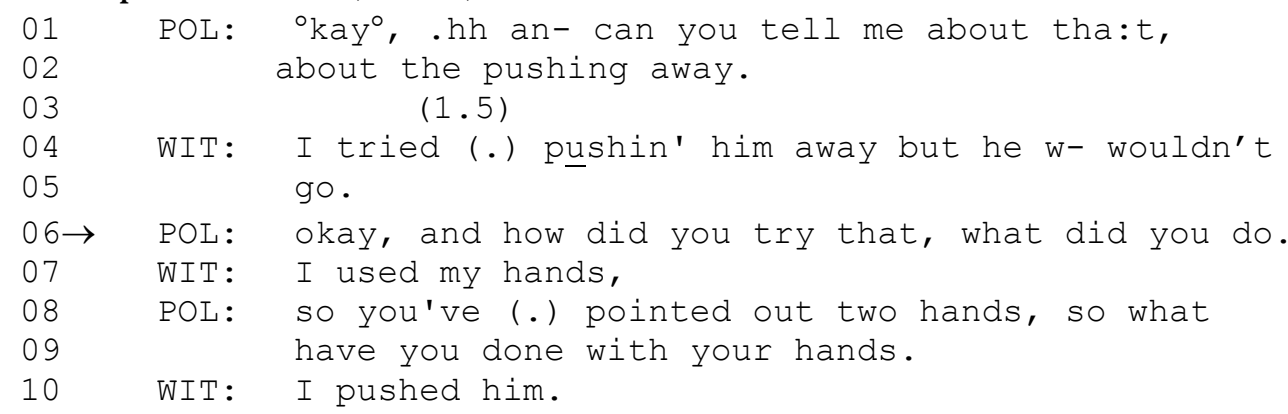


The witness's answer that she tried 'pushing him away' would normally be taken, without second thought, to imply that she used her hands (it would be odd to imagine that "push" in this context would involve any other part of the body); but PO does not rely on that inference, and issues a further (open-ended) question at line 6 . Although the witness now gives what sounds like a clear answer, the PO settles the matter by themselves articulating "two hands" for the benefit of the tape (see above for the way such formulas enter the police tapes). That puts beyond doubt that she acted normally, disarming any subsequent claim that the witness might have meant some less conventionally-obvious sense of 'pushing', which, if it came to court, defence counsel could argue was easily misconstruable by their client.

Example 23 below is more graphic. Here the witness seems insistent on keeping to a euphemism - allowable in everyday conversation - but is pressed by the PO to use a more formal word.

Example 23. WIT 6, 810, 25.10

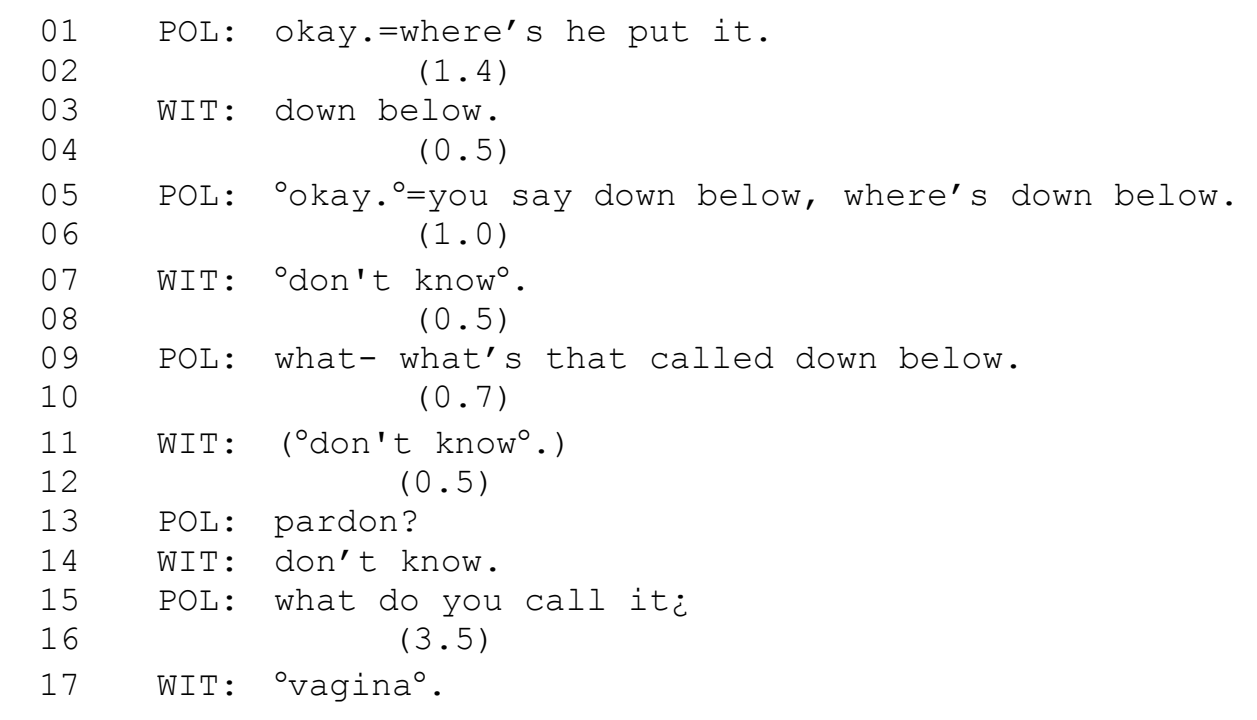

At lines 3, 7 and 11, the witness falls back on "don't know", which might be true; she might not have been taught the anatomical names of her private parts, or might have forgotten them. So PO might accept that the witness is admitting to failing the quality maxim (perhaps specifically the sub-maxim of having an evidential base (Grice 1989 p 27) . Nevertheless P0 pursues the matter, and eventually gets the witness to pronounce the word vagina, disarming a possible later quibble about exact location, that the alleged perpetrator's defence counsel might raise.

\section{Contrast case}

In a very few cases, the course of the interview will reveal that the PO should have doubted the cooperativeness of the IE's original answer - but didn't. In the case below, the IE's answer at line 10 indicate that she was alone when she entered the park, yet it becomes clear two turns later that, in fact, she was at that point accompanied by the person who she alleges would later assault her. 
Example 24. WIT 14, 309, 17.45

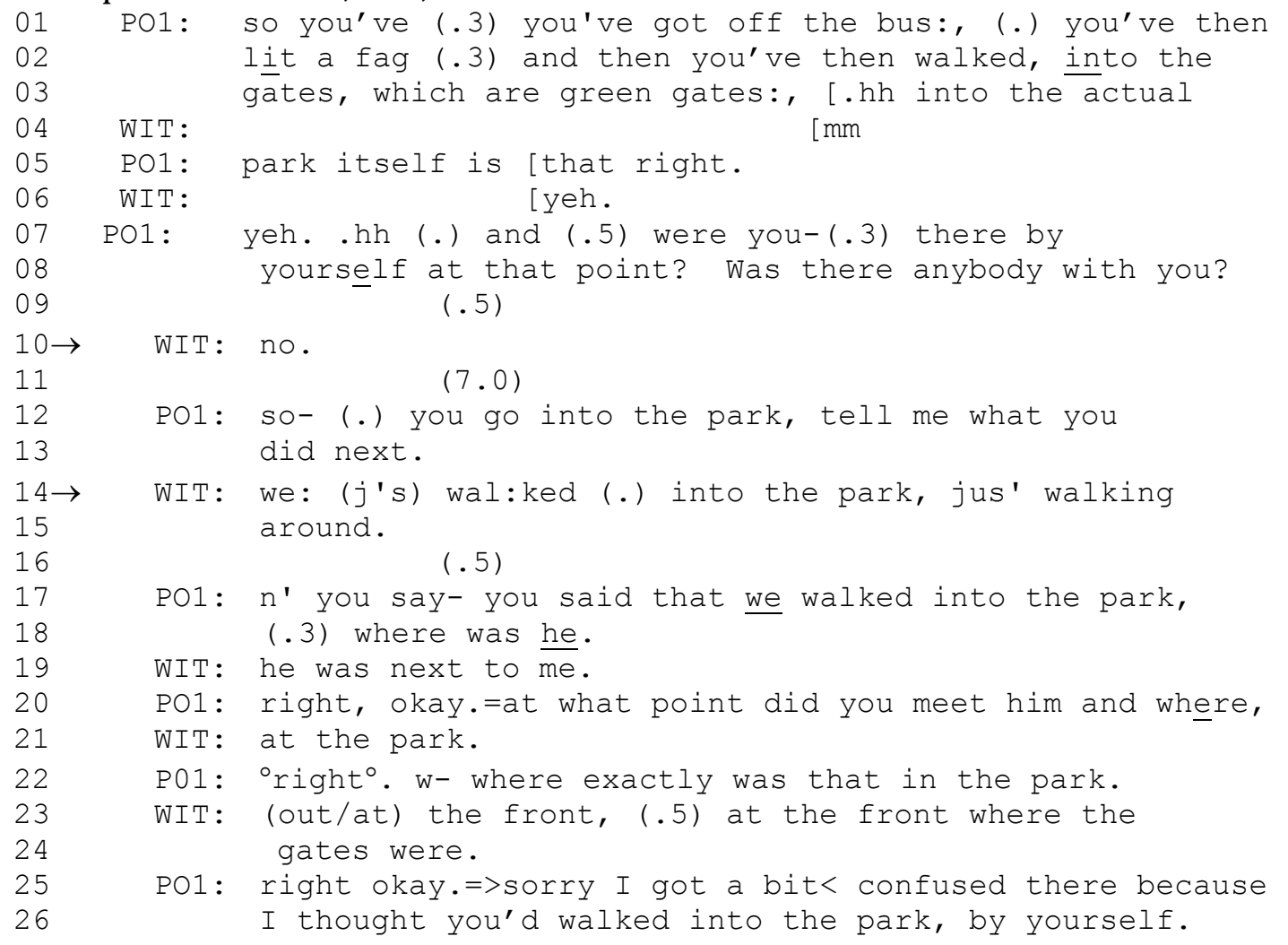

The PO quickly recognises that there is a contradiction in WIT's account between lines 10 and 14, and at that point probes further (and later explains why she has done so). It is a rare case of significant information being (at first) missed because the the interviewer assumed that the interviewee was abiding by the maxims of co-operation - although (for reasons of her intellectual disability, or just ordinary mis-speaking) she wasn't.

\section{$\underline{\text { Discussion }}$}

Institutional constraints on conversation necessarily distort the everyday contract that people have with each other, and such distortions may entail a problem for the institutional representatives. In the case of police interviewers, the standing orders of the UK College of Policing interviewing guidelines require that a balance be struck between establishing rapport with the interviewee (whether suspect or witness) and extracting the fullest amount of forensically relevant information. This article set out to discover how, in formal police interviews, the interviewer on occasion decided the dilemma in favour of suspending the presumption of their interlocutors' co-operation, in spite of the risk to rapport with the interviewee.

The Gricean presumption of co-operative conversation would normally be in force in everyday interaction, and arguably also in institutions where the interviewer has no mandate to arrive at a version of events that might be being knowingly occluded by the interlocutor. Houtkoop, for example, shows how the 
survey interviewer will, on occasion, design their questions optimistically (thus reading and writing, you've managed all right? [Houtkoop, 1995 p 595]); Heritage and Lindstrom (1998) first charted UK health visitors' personnel's use of what they called 'optimistic format' questions, and this has long been familiar as a feature of primary care medical consultation (thus, about giving birth: you didn't have forceps, Boyd and Heritage (2006, p 175). In those cases it might well be argued that the practitioner's institutional objectives to build rapport and get the required information (for the survey, for the diagnosis) go reasonably well hand in hand ${ }^{3}$.

But the special forensic status of police interviews makes scepticism a more efficient strategy 4 . Sometimes this 'efficiency' may actually reveal more exculpatory, rather than incriminating, evidence; Howarth (2017) gives a vivid case-study of an interviewer providing a suspect with questions that solicited a more innocent version of events than had theretofore emerged (rather than, as in our cases, the questions tending to presume and reveal more guilt). She argues that - given this was a rape suspect - "this went beyond testing whether a valid defence might exist and towards actively constructing one" (p. 18), although accepts that it might nevertheless be true. One way or the other, though, her study underscores the directive power of the interviewers' questions - in her case, towards benign information; in ours, just the reverse.

We concentrated on police officers' follow-up questions, specifically those that seemed to query what would (in everyday conversation) seem to be wholly unexceptionable answers. Thus the interviewee might be asked (as in Example 6) if who was with them in the car, and would reply my girlfriend; in noninstitutional settings this would be taken to be the whole truth, on the assumption that the interviewee was observing normal Gricean maxims. But here the police interviewer did not make that assumption, and asked explicitly whether there was anyone else in the car too.

We identified three institutional benefits delivered by such sceptical probings of apparently unexceptionable answers. The most neutral was simply ironing out the basic run of events, to straighten everyday narrative into the kind of detailed chronology that would be appropriate for the court. That was perhaps the most expectable and standard effect, quite consistent with the requirements of PACE and the College of Policing's guidelines on interviewing. More tendentiously, a probe served to get the suspect to confirm their own version of events, so that the police interviewer could then more tellingly reveal a contradiction with other evidence. Most directly in line with the forensic nature of the interview, probes of apparently normal answers could yield a version of events that indicated more clearly what criminal charge could be brought (whether against the suspect being interviewed, or against the perpetrator by whom the witness alleged they had been assaulted). In a number - but not all - of the cases we listed, the PO's scepticism was in fact justified. The original answer would in such cases turn out to be deficient in quantity (that the suspect had in fact bought more alcohol than

\footnotetext{
3 Though see, for example, Nielsen (2016) on how that can be disrupted by doctors' use of information technology to check records etc. during the consultation
} 
they originally claimed), manner (the suspect had in fact hit a tree, not swiped it) and relevance (the suspect's denial that he had not seen his alleged victim on his knees didn't answer the question of whether he clenched his fist - which he did).

That police interviewers have robust powers of questioning is hardly a new discovery - scholarly studies such as Howarth's (see above) regularly reveal new subtleties in the kind of force revealed by Heydon's pioneering account (Heydon 2005). The point of what we were able to identify here is the specific one of the use of counter-Gricean questioning and so help locate just what it is about police interviews (among other interviews, such as aggressive news interviews, where the need for information trumps the need to stay friendly) that strikes one as being 'hostile' . Unlike the news interview, here the interviewer's objectives are legally entailed, and that perhaps explains why, in the overwhelming majority of cases in our data, interviewees seem not to be audibly upset by the questions or offer particular resistance to them ${ }^{5}$. This must remain speculation, of course, and we only have access to the audio-tape, and can make no confident judgement about what people really felt. Nevertheless, it may be that the paraphernalia of the interview set up, its location in the police station, and the reading-out of the caution at the start of proceedings, seems to cement in all participants' minds that, unlike the everyday world, here the presumption of co-operativeness may be suspended without notice.

\section{$\underline{\text { References }}$}

Antaki, C, Richardson, E, Stokoe, E.H. and Willott, S. (2015) Police interviews with vulnerable people alleging sexual assault: probing inconsistency and questioning conduct. Journal of Sociolinguistics, 19, 328-350

Boyd, E. and Heritage J (2006). Analyzing history-taking in primary care: questioning and answering during verbal examination. In J. Heritage and D. Maynard (Eds) Communication in Medical Care: Interaction Between Primary Care Physicians and Patients, Cambridge, CUP 151-184.

Clayman, S. E., Elliott, M. N., Heritage, J., \& McDonald, L. L. (2006). Historical Trends in Questioning Presidents, 1953-2000. Presidential Studies Quarterly, 36(4), 561-583.

College of Policing (UK) Authorised Professional Practice: Investigative Interviewing. https://www.app.college.police.uk/appcontent/investigations/investigative-interviewing/\# (Accessed \& downloaded May 2016)

Drew, P. and Heritage, J (1992). Analyzing talk at work: an introduction. P. Drew \& J. Heritage (Eds.) In Talk at work: Interaction in institutional settings (s. 3-65) Cambridge: Cambridge University Press.

\footnotetext{
${ }^{5}$ Compare, for example, politicians' responses to what Romainuk (2013, p 153) calls news interviewers 'tightening the reins'
} 
Drew, P. (1992). John Heritage (Eds.), Talk at Work. Interaction in Institutional Settings, CUP, Cambridge.

Grice, H. P. (1975/1989). Logic and Conversation. Reprinted in Studies in the Way of Words, ed. HP Grice.(1989). Cambridge, Mass: Harvard University Press

Ten Have, P. (2007). Doing conversation analysis. London: Sage.

Hepburn, A., Wilkinson, S., \& Butler, C. W. (2014). Intervening with conversation analysis in telephone helpline services: Strategies to improve effectiveness. Research on Language and Social Interaction, 47(3), 239-254.

Heritage, J. C., \& Watson, D. R. (1980). Aspects of the properties of formulations in natural conversations: Some instances analysed. Semiotica, 30(3-4), 245-262.

Heritage, J., \& Lindstrom, A. (1998). Motherhood, medicine, and morality: Scenes from a medical encounter. Research on Language \& Social Interaction, 31(3-4), 397-438.

Heritage, J., \& Raymond, G. (2005). The terms of agreement: Indexing epistemic authority and subordination in talk-in-interaction. Social psychology quarterly, 68(1), 15-38.

Heydon,G (2005) The Language of Police Interviewing: a critical analysis. Basingstoke: Palgrave

Houtkoop-Steenstra, H. (1997). Being friendly in survey interviews. Journal of Pragmatics, 28(5), 591-623.

Haworth, K. (2017). The discursive construction of evidence in police interviews: Case study of a rape suspect. Applied Linguistics, 38 (2): 194-214

Jefferson, G (2004) Glossary of transcript symbols with an introduction. In G H Lerner (ed) Conversation Analysis: Studies from the first generation. Amsterdam: John Benjamins

Liddicoat, A. J. (2011). An Introduction to Conversation Analysis. London: Continuum

Levinson, S. C. (1992). Activity types and language. In Talk at work: Interaction in institutional settings (pp. 66-100). Cambridge: Cambridge University Press.

Marmor, A. (2009). Social conventions: From language to law. Princeton: Princeton University Press.

Maynard, D. W., \& Heritage, J. (2005). Conversation analysis, doctor-patient interaction and medical communication. Medical education, 39(4), 428-435. 
Moeschler, J. (2013). Is a speaker-based pragmatics possible? Or how can a hearer infer a speaker's commitment?. Journal of Pragmatics, 48(1), 84-97.

Nielsen, S. B. (2016). How Doctors Manage Consulting Computer Records While Interacting With Patients. Research on Language and Social Interaction, 49(1), 58-74.

Raymond, G. (2003). Grammar and social organization: Yes/no interrogatives and the structure of responding. American sociological review, 939-967.

Romaniuk, T. (2013). Pursuing answers to questions in broadcast journalism. Research on Language \& Social Interaction, 46(2), 144-164.

Sperber, D., \& Wilson, D. (1986/1995). Relevance: Communication and cognition. Oxford: Blackwell. Second edition.

Stokoe, E., \& Edwards, D. (2008). Did you have permission to smash your neighbour's door? 'Silly questions and their answers in police-suspect interrogations. Discourse Studies, 10(1), 89-111.

UK Ministry of Justice (2011) Achieving Best Evidence in Criminal Proceedings. London: HMSO http://www.justice.gov.uk/downloads/victims-andwitnesses/vulnerable-witnesses/achieving-best-evidence-criminalproceedings.pdf [accessed \& downloaded June 2014] 